Research

Open Access

\title{
S-100B and neuron-specific enolase as predictors of neurological outcome in patients after cardiac arrest and return of spontaneous circulation: a systematic review
}

\author{
Koichiro Shinozaki, Shigeto Oda, Tomohito Sadahiro, Masataka Nakamura, Yo Hirayama, \\ Ryuzo Abe, Yoshihisa Tateishi, Noriyuki Hattori, Tadanaga Shimada and Hiroyuki Hirasawa
}

\author{
Department of Emergency and Critical Care Medicine, Graduate School of Medicine, Chiba University, 1-8-1 Inohana, Chuo-ku, Chiba City, 260- \\ 8677, Japan \\ Corresponding author: Koichiro Shinozaki, shino@gk9.so-net.ne.jp \\ Received: 14 Apr 2009 Revisions requested: 24 May 2009 Revisions received: 4 Jun 2009 Accepted: 22 Jul 2009 Published: 22 Jul 2009 \\ Critical Care 2009, 13:R121 (doi:10.1186/cc7973) \\ This article is online at: http://ccforum.com/content/13/4/R121 \\ (c) 2009 Shinozaki et al.; licensee BioMed Central Ltd. \\ This is an open access article distributed under the terms of the Creative Commons Attribution License (http://creativecommons.org/licenses/by/2.0), \\ which permits unrestricted use, distribution, and reproduction in any medium, provided the original work is properly cited.
}

\begin{abstract}
Introduction Neurological prognostic factors after cardiopulmonary resuscitation (CPR) in patients with cardiac arrest (CA) as early and accurately as possible are urgently needed to determine therapeutic strategies after successful CPR. In particular, serum levels of protein neuron-specific enolase (NSE) and S-100B are considered promising candidates for neurological predictors, and many investigations on the clinical usefulness of these markers have been published. However, the design adopted varied from study to study, making a systematic literature review extremely difficult. The present review focuses on the following three respects for the study design: definitions of outcome, value of specificity and time points of blood sampling.
\end{abstract}

Methods A Medline search of literature published before August 2008 was performed using the following search terms: "NSE vs CA or CPR", "S100 vs CA or CPR". Publications examining the clinical usefulness of NSE or S-100B as a prognostic predictor in two outcome groups were reviewed. All publications met with inclusion criteria were classified into three groups with respect to the definitions of outcome; "dead or alive", "regained consciousness or remained comatose", and "return to independent daily life or not". The significance of differences between two outcome groups, cutoff values and predictive accuracy on each time points of blood sampling were investigated.

Results A total of 54 papers were retrieved by the initial text search, and 24 were finally selected. In the three classified groups, most of the studies showed the significance of differences and concluded these biomarkers were useful for neurological predictor. However, in view of blood sampling points, the significance was not always detected. Nevertheless, only five studies involved uniform application of a blood sampling schedule with sampling intervals specified based on a set starting point. Specificity was not always set to $100 \%$, therefore it is difficult to indiscriminately assess the cut-off values and its predictive accuracy of these biomarkers in this meta analysis.

Conclusions In such circumstances, the findings of the present study should aid future investigators in examining the clinical usefulness of these markers and determination of cut-off values.

\section{Introduction}

Identifying neurological prognostic factors after cardiopulmonary resuscitation (CPR) in patients with cardiac arrest (CA) as early and accurately as possible is urgently needed to determine therapeutic strategies after successful CPR and avoid medical futility. Many investigators have previously attempted to establish them $[1,2]$.

Epidemiological data on CA are generally accumulated according to the Utstein Templates [3-5], and retrospective analysis of these data allows, to a certain extent, prognostic

CA: cardiac arrest; CPC: cerebral performance categories; CPR: cardiopulmonary resuscitation; CSF: cerebrospinal fluid; GCS: Glasgow coma scale; GOS: Glasgow outcome scale; NSE: neuron-specific enolase; ROC: receiver-operating characteristics; ROSC: return of spontaneous circulation. 
prediction of the patients following CA $[6,7]$. In fact, it is difficult to decide on therapeutic measures for a particular patient based solely on information obtained using the Utstein Templates, due to limitations including: the scope of these templates for registry of cases of CA are limited to individuals with disease categorized as 'cardiac etiology' and 'witnessed arrest; and the specificity of prognostic parameters examined is not satisfactory [1].

Although most of the data specified in the Utstein Templates are collected prior to 'return of spontaneous circulation' (ROSC), data obtained after ROSC also provide valuable information on the prognosis of individual patients. Therefore, the latest version of the Utstein Templates highlighting postresuscitative care recommends development of a special template for collection and recoding of data in the post-resuscitation phase [8]. Neuroimaging data (e.g., brain computed tomography and magnetic resonance imaging), electrophysiological data (e.g., electroencephalography, auditory brainstem response recording, and somatosensory evoked potential recording), and blood or cerebrospinal fluid (CSF) examination data (i.e., levels of proteins specific to the central nervous system) $[1,2]$ have been tested for clinical usefulness as neurological prognostic predictors by many investigators, although they are all classified as 'supplementary data' in the latest version of the Utstein Templates.

Neuroimaging requires transfer of the patient to a dedicated examination site equipped with special devices, which makes it difficult to apply it to individuals who are receiving high doses of inotropes or circulatory support with an extracorporeal device. Acquisition and analysis of electrophysiological data requires qualified specialists in particular medical fields, making it difficult to perform such examinations in individuals presenting after weekday clinic hours. In contrast, laboratory data are easily obtained with high reproducibility as a part of normal intensive care routine, a feature favorable for clinical application. Considering the extent of insult associated with sample collection, blood may be preferable to CSF.

Serum levels of protein neuron-specific enolase (NSE) and S$100 \mathrm{~B}$ are considered promising candidates for neurological prognostic predictors in patients with ROSC after CPR, and many investigations on the clinical usefulness of these biochemical markers in predicting neurological outcomes after CPR have been published $[1,9,10]$. In the present study, we performed an extensive literature review to examine the clinical usefulness of NSE and S-100B as post-resuscitation neurological prognostic predictors.

To improve applicability of study results in clinical practice, we considered the following three points when designing the present study: a consistent definition of poor (good) outcome should be used in assessing data from multiple studies; the cut-off values for biochemical markers should be set so that specificity in prediction of poor outcome is 100\%; and the time points of blood sampling should be fixed in assessing the time course of change in blood levels of biochemical markers. Although few reviews of application of biological markers to prediction of neurological outcome in CA after CPR published meet the above requirements $[1,10]$, the present study is the first extensive literature review that does meet them.

\section{Materials and methods Literature search}

A Medline search of literature published before August 2008 was performed using the following search terms: 'neuron-specific enolase and cardiac arrest', 'neuron-specific enolase and cardiopulmonary resuscitation', 'NSE and cardiac arrest', and 'NSE and cardiopulmonary resuscitation' with respect to NSE, and 'S100 and cardiac arrest' and 'S100 and cardiopulmonary resuscitation' with respect to $\mathrm{S}-100 \mathrm{~B}$. Cross-references were retrieved from the studies and reviews thus identified. The search included all types of publications (reviews, original studies, case reports, and editorials), but excluded those not in English and animal experimental studies. One author (KS) performed the selection and reviewed all full-text papers.

\section{Selection of studies}

Publications examining the clinical usefulness of NSE or S$100 \mathrm{~B}$ as a prognostic predictor in two outcome groups, 'favorable outcome' and 'poor outcome', were reviewed, with case reports excluded at this stage. When a study examined a prognostic predictor (or predictors) other than NSE and S-100B as well, only the results for NSE and/or S-100B were reviewed.

\section{Definition of outcome}

Cerebral performance was evaluated according by Cerebral Performance Categories (CPC) 1 to 5 of the Glasgow-Pittsburgh Outcome Categories [11] and the Glasgow Outcome Scale [12,13] (GOS) scores 1 to 5 , as recommended by the Utstein Template [4]. The relations between the corresponding grades in the two different grading systems were considered to be as follows. CPC 1 ('good cerebral performance: conscious and alert with normal neurological function or only slight cerebral disability') was equivalent to GOS 5 ('good recovery: able to return to work or school'). CPC 2 ('moderate cerebral disability: conscious and sufficient cerebral function for part-time work in sheltered environment or independent activities of daily life') was equivalent to GOS 4 ('moderate disability: able to live independently but unable to return to work or school'). CPC 3 ('severe cerebral disability: conscious and dependent on others for daily support because of impaired brain function') was equivalent to GOS 3 ('severe disability: able to follow commands but unable to live independently'). CPC 4 and GOS 2 (both defined as 'coma, vegetative state') were mutually equivalent. CPC 5 and GOS 1 (both defined as 'dead or brain dead') were mutually equivalent. 
When a study to be reviewed did not involve evaluation of cerebral performance according to either CPC or GOS, one author (KS) assigned the grade that appeared most appropriate as judged from the description in the original article. The actual time point of assessment of cerebral performance as study endpoint, which varied from study to study, was used in the present review as it was in the original text.

In general, outcome after CA is defined dichotomously in the following three respects: dead or alive (survival); regained consciousness or remained comatose (consciousness); and return to independent daily life or not.

To fit this dichotomous system of description, the neurological outcome graded in each study according to CPC, GOS, and Glasgow Coma Scale (GCS) was further grouped for the present review as follows: 'dead': died in hospital; 'alive': survival at the endpoint defined in each study; 'remained comatose': CPC 4 or 5, GOS 1 or 2 (persistent coma, GCS score 57); 'regained consciousness': CPC 1 to 3 , GOS 3 to 5 (obeying simple verbal commands, GCS score $\geq 8$ ); 'no return to independent daily life': CPC 3 to 5 , GOS 1 to 3 ; 'return to independent daily life': CPC 1 or 2 , GOS 4 or 5 .

\section{Classification of sampling points}

The various sampling time points in individual studies were classified into the following six categories for the sake of simplicity: (1) 'on admission': time points described as 'on admission', 'day 0', or 'within 8 hours after $\mathrm{CA}^{\prime}$; (2) 'day 1': time points described as 'day 1' or 'at or within 12 hours after CA'; (3) '24 hours': time points described as 'at 24 hours \pm 4 hours'; (4) 'day 2': time points described as 'day 2', 'at 36 hours', or 'between 24 and 48 hours'; (5) '48 hours': time points described as 'at 48 hours \pm 4 hours'; (6) 'day 3': time points described as 'day 3 ' or 'at 60 hours'.

\section{Statistical analysis}

Results of statistical comparison between two outcome groups are cited in the present study as reported in the original article, with $P$ values presented after classification into the following three categories for simplicity: not significant $(\geq 0.05)$; $<0.05$; and $<0.01$. The cut-off value for serum level of NSE or S-100B predictive of a poor outcome ('dead', 'remained comatose' or 'no return to independent daily life') was cited as being reported in each original article, together with the corresponding values of sensitivity, specificity, and accuracy calculated using a $2 \times 2$ contingency table. When the original article reported only raw data (i.e., serum level of a particular biochemical marker and outcomes of individual patients), we determined the significance of the difference between two outcome groups with the unpaired $t$-test or the Mann-Whitney $U$ test as appropriate, and further calculated the cut-off value for serum level of each biochemical marker predictive of poor outcome with a specificity of $100 \%$ by receiver-operating characteristics (ROC) analysis. A two-tailed $P$ value of $<0.05$ was considered significant. All statistical analyses were carried out using SPSS software (SPSS Japan Inc., Tokyo, Japan).

\section{Results}

A total of 54 papers were retrieved by the initial text search, and 29 of them met the selection criteria. After these 29 papers were reviewed in full text and searched for cross-references, 31 papers were finally selected for the present review. The full-text contents of all 31 papers, which included 26 original articles [14-39] and five review articles [1,2,9,10,40], were reviewed and compared. Twenty-one original articles [14,18,21-39] investigated NSE, while 14 [14$20,22,25,26,28,29,31,39]$ investigated S-100B. Articles by Mussack and colleagues [19] and Hachimi-Idrissi and colleagues [15] were excluded from further review because they reported serum levels of $\mathrm{S}-100 \mathrm{~B}$ in patients with $\mathrm{CA}$ after CPR but without comparison between different outcome groups. Therefore, we systematically reviewed a total of 24 original articles.

Generally, systematic review articles seemed not to contain any more data or results than original reports. However, inclusion of all previously published papers is one of the main purposes of this study, and therefore all the review articles were subjected to the cross-referencing and those articles were included in this study.

\section{'Dead' vs 'Alive'}

Four studies [14,18,20,24] investigated the clinical usefulness of NSE and/or S-100B as a prognostic predictor for two outcome groups, 'dead' and 'alive'. Table 1 summarizes the results of statistical comparison of serum levels of each biochemical marker between the two groups. Table 2 indicates cut-off values for individual biochemical markers predicting death with the corresponding values of sensitivity, specificity, and accuracy.

The clinically useful outcome that can be predicted using NSE and/or S-100B, which are biomarkers specific to the central nervous system, is neurological outcome rather than survival outcome. Consequently, association of these biomarkers with survival outcome was investigated in a limited number of studies. Grubb and colleagues [14] demonstrated in a study involving a relatively large number of subjects $(n=143)$ that $S$ $100 B$ assayed on day 2 was slightly superior to NSE assayed concomitantly with respect to predictive accuracy for mortality.

\section{'Regained consciousness' vs. 'Remained comatose'}

Sixteen studies [16,21-23,25,27,28,31-39] investigated the clinical usefulness of NSE and/or S-100B as a prognostic predictor in two outcome groups, 'regained consciousness' and 'remained comatose'. Table 3 summarizes the results of statistical comparison of serum levels of each biochemical marker between the two groups. Table 4 indicates cut-off values for 
Table 1

Comparison of values for biomarkers between dead and alive

\begin{tabular}{|c|c|c|c|c|c|c|c|c|c|}
\hline Authors & Year & Ref & $\mathrm{n}$ & on admission & Day 1 & 24 hours & Day 2 & 48 hours & Day 3 \\
\hline \multicolumn{10}{|l|}{ NSE } \\
\hline Grubb and colleagues & 2007 & [14] & 143 & - & $P<0.01$ & - & $P<0.01$ & - & - \\
\hline Auer and colleagues & 2006 & {$[24]$} & 17 & NS & NS & - & $P<0.05$ & - & - \\
\hline \multicolumn{10}{|l|}{ S-100B } \\
\hline Grubb and colleagues & 2007 & {$[14]$} & 143 & - & $P<0.01$ & - & $P<0.01$ & - & - \\
\hline Bottiger and colleagues & 2001 & [18] & 66 & NM & - & NM & - & NM & - \\
\hline Rosen and colleagues & 1998 & [20] & 41 & - & $P<0.01$ & - & $P<0.01$ & - & $P<0.01$ \\
\hline
\end{tabular}

$\mathrm{NM}=$ not mentioned for statistical comparison; NS = not significance; NSE = neuron specific enolase; Ref $=$ references.

individual biochemical markers predicting persistent coma with the corresponding values of sensitivity, specificity, and accuracy.

In addition to those reporting cut-off values according to time course interval listed in Table 4, the following four studies investigated the clinical usefulness in predicting neurological outcome after CPR not in accordance with time course interval. Reisinger and colleagues [21] assayed serum NSE concentrations at five different time points after CPR (from ICU admission to day 4), although without statistical comparison between different outcome groups, to determine the cut-off value for peak NSE concentration within these five points predictive of 'persistent coma (CPC 4)' with a specificity of $100 \%$. They reported that a peak NSE concentration more than $80 \mathrm{ng} / \mathrm{mL}$ (noted by day 4) was invariably associated with 'persistent coma', that is, no patients meeting this criterion regained consciousness. They further concluded, based on the results of ROC analysis, that a cut-off value of $80 \mathrm{ng} / \mathrm{mL}$ for peak NSE concentration predicted 'persistent coma' at a specificity of $100 \%$ with a sensitivity of $63 \%$ and a predictive accuracy of $88 \%$. Zandbergen and colleagues [22] assayed serum NSE and S-100B concentrations at three different time points $(24,48$, and 72 hours after CPR) and reported a cut-off value for peak NSE concentration within these three points, 33 $\mathrm{ng} / \mathrm{mL}$, corresponding to a positive predictive value of $100 \%$ and a cut-off value for peak S-100B concentration of $0.7 \mathrm{ng} /$ $\mathrm{mL}$ corresponding to a positive predictive value of $98 \%$. Meynaar and colleagues [27] reported that no patient with a serum NSE level of more than $25 \mathrm{ng} / \mathrm{mL}$ at 24 or 48 hours after CPR regained consciousness (specificity 100\%, sensitivity 59\%). Bassetti and colleagues [33], who determined serum NSE concentrations at two different time points (12 and 24 hours after (CPR), referred to a positive predictive value for a serum NSE concentration exceeding the normal level at each time point without calculation of a cut-off value.

Table 2

\begin{tabular}{|c|c|c|c|c|c|c|}
\hline Authors & $\begin{array}{c}\text { On admission } \\
\text { cut/spe/sen/acc }\end{array}$ & $\begin{array}{c}\text { Day } 1 \\
\text { cut/spe/sen/acc }\end{array}$ & $\begin{array}{c}24 \text { hours } \\
\text { cut/spe/sen/acc }\end{array}$ & $\begin{array}{c}\text { Day } 2 \\
\text { cut/spe/sen/acc }\end{array}$ & $\begin{array}{c}48 \text { hours } \\
\text { cut/spe/sen/acc }\end{array}$ & $\begin{array}{c}\text { Day } 3 \\
\text { cut/spe/sen/acc }\end{array}$ \\
\hline \multicolumn{7}{|l|}{ NSE } \\
\hline Grubb and colleagues & - & NM & - & $(24) / 86 / 60 / 72$ & - & - \\
\hline Grubb and colleagues & - & NM & - & $(71) / 100 / 14 / 54$ & - & - \\
\hline Auer and colleagues & NM & NM & - & (30)/100/79/88 & - & - \\
\hline \multicolumn{7}{|l|}{ S-100B } \\
\hline Grubb and colleagues & - & NM & - & $(0.3) / 76 / 73 / 75$ & - & - \\
\hline Grubb and colleagues & - & NM & - & $(1.2) / 100 / 45 / 74$ & - & - \\
\hline Bottiger and colleagues & $(0.2) / 45 / 100 / 82$ & - & $(0.2) / 80 / 100 / 91$ & - & $(0.2) / 70 / 100 / 84$ & - \\
\hline Rosen and colleagues & - & $(0.2) / 81 / 77 / 79$ & - & $(0.2) / 100 / 79 / 92$ & - & NM \\
\hline
\end{tabular}

Values in bold are the results of our calculation. cut = values of cutoff points $(\mathrm{ng} / \mathrm{mL})$; spe = specificity $(\%)$; sen = sensitivity $(\%)$; acc $=$ accuracy (\%).

$\mathrm{NM}=$ not mentioned for cutoff values and predictive accuracy; NSE $=$ neuron specific enolase. 
Table 3

Comparison of values for biomarkers between remained coma and regained consciousness

\begin{tabular}{|c|c|c|c|c|c|c|c|c|c|}
\hline Authors & Year & Ref & $\mathrm{n}$ & on admission & Day 1 & 24 hours & Day 2 & 48 hours & Day 3 \\
\hline \multicolumn{10}{|l|}{ NSE } \\
\hline Reisinger and colleagues & 2007 & [21] & 227 & NM & NM & - & NM & - & NM \\
\hline Prohl and colleagues & 2007 & [39] & 80 & - & $P<0.01$ & - & $P<0.01$ & - & $P<0.01$ \\
\hline Zandbergen and colleagues & 2006 & {$[22]$} & 407 & - & - & NM & - & NM & - \\
\hline Rech and colleagues & 2006 & [23] & 45 & - & - & $P<0.01$ & - & - & - \\
\hline Pfeifer and colleagues & 2005 & [25] & 97 & - & $P<0.05$ & - & $P<0.05$ & - & $P<0.05$ \\
\hline Meynaar and colleagues & 2003 & [27] & 110 & NS & - & $P<0.01$ & - & $P<0.01$ & - \\
\hline Zingler and colleagues & 2003 & [28] & 27 & NS & $P<0.05$ & - & $P<0.05$ & - & - \\
\hline Martens and colleagues & 1998 & [31] & 64 & - & - & $P<0.01$ & - & - & - \\
\hline Fogel and colleagues & 1997 & [32] & 50 & $P<0.01$ & $P<0.01$ & - & $P<0.01$ & - & $P<0.01$ \\
\hline Martens & 1996 & [34] & 52 & - & - & $P<0.01$ & - & - & - \\
\hline Bassetti and colleagues & 1996 & [33] & 60 & - & NM & NM & - & - & - \\
\hline Stelzl and colleagues & 1995 & [35] & 13 & NS & $P<0.05$ & $P<0.05$ & $P<0.05$ & $P<0.05$ & $P<0.05$ \\
\hline Karkela and colleagues & 1993 & [36] & 20 & NS & - & NS & - & - & - \\
\hline Dauberschmidt and colleagues & 1991 & [37] & 18 & NS & NS & - & NS & - & NS \\
\hline Roine and colleagues & 1989 & [38] & 75 & - & - & $P<0.01$ & - & - & - \\
\hline \multicolumn{10}{|l|}{ S-100B } \\
\hline Prohl and colleagues & 2007 & [39] & 80 & - & $P<0.01$ & - & $P<0.01$ & - & $P<0.01$ \\
\hline Zandbergen and colleagues & 2006 & [22] & 407 & - & - & NM & - & NM & - \\
\hline Pfeifer and colleagues & 2005 & {$[25]$} & 97 & - & NS & - & $P<0.05$ & - & $P<0.05$ \\
\hline Zingler and colleagues & 2003 & {$[28]$} & 27 & $P<0.05$ & $P<0.01$ & - & $P<0.05$ & - & - \\
\hline Hachimi-Idrissi and colleagues & 2002 & [16] & 58 & $P<0.01$ & - & $P<0.01$ & - & - & - \\
\hline Martens and colleagues & 1998 & [31] & 64 & - & - & $P<0.01$ & - & - & - \\
\hline
\end{tabular}

Values in bold are the results of our calculation. $\mathrm{NM}=$ not mentioned for statistical comparison; $\mathrm{NS}=$ not significance; NSE $=$ neuron specific enolase; Ref $=$ references.

The number of studies comparing the two neurological outcome groups, 'remained comatose' vs. 'regained consciousness', was 16, and greater than the number of studies comparing any other pair of outcome groups. Of these 16 studies, seven reported serum NSE levels on admission, while two reported serum S-100B levels on admission. One study $(1 / 7,14.3 \%)$ detected a significant difference in NSE on admission between the two outcome groups, while two studies $(2 / 2,100 \%)$ identified a significant difference in S-100B on admission. On the other hand, five studies $(5 / 7,71.4 \%)$ failed to detect a significant difference between groups in NSE on admission, while no study failed to detect such a difference in S-100B on admission (Table 3). These findings suggest that $\mathrm{S}-100 \mathrm{~B}$ assayed on admission may be more useful than NSE assayed concomitantly as an early biochemical predictor of success or failure in regaining consciousness. The reported values of predictive accuracy corresponding to a cutoff value on admission for S-100B prediction of persistent coma with $100 \%$ specificity in the study by Zingler and colleagues [28] is a little higher (59\%) than that for NSE (56\%) in the study by Fogel and colleagues [32] those detected a significant difference between the two outcome groups.

At no sampling time point other than 'on admission' any particular tendency was noted with respect to the clinical usefulness of NSE and S-100B as neurological prognostic predictors. 
Critical Care Vol 13 No 4 Shinozaki et al.

Table 4

\begin{tabular}{|c|c|c|c|c|c|c|}
\hline Authors & $\begin{array}{c}\text { on admission } \\
\text { cut/spe/sen/acc }\end{array}$ & $\begin{array}{c}\text { Day } 1 \\
\text { cut/spe/sen/acc }\end{array}$ & $\begin{array}{c}24 \text { hours } \\
\text { cut/spe/sen/acc }\end{array}$ & $\begin{array}{c}\text { Day } 2 \\
\text { cut/spe/sen/acc }\end{array}$ & $\begin{array}{c}48 \text { hours } \\
\text { cut/spe/sen/acc }\end{array}$ & $\begin{array}{c}\text { Day } 3 \\
\text { cut/spe/sen/acc }\end{array}$ \\
\hline \multicolumn{7}{|l|}{ NSE } \\
\hline $\begin{array}{l}\text { Reisinger and } \\
\text { colleagues }\end{array}$ & NM & NM & - & NM & - & NM \\
\hline $\begin{array}{l}\text { Prohl and } \\
\text { colleagues }\end{array}$ & - & $(29) / 100 / 33 / 78$ & - & (32)/100/33/78 & - & $(28) / 100 / 67 / 89$ \\
\hline $\begin{array}{l}\text { Zandbergen and } \\
\text { colleagues }\end{array}$ & - & - & NM & - & NM & - \\
\hline $\begin{array}{l}\text { Rech and } \\
\text { colleagues }\end{array}$ & - & - & $(60) / 100 / 35 / 49$ & - & - & - \\
\hline $\begin{array}{l}\text { Pfeifer and } \\
\text { colleagues }\end{array}$ & - & NM & - & NM & - & (65)/96/40/56 \\
\hline $\begin{array}{l}\text { Meynaar and } \\
\text { colleagues }\end{array}$ & NM & - & NM & - & NM & - \\
\hline $\begin{array}{l}\text { Zingler and } \\
\text { colleagues }\end{array}$ & $(48) / 100 / 53 / 70$ & $(43) / 100 / 91 / 94$ & - & $(91) / 100 / 75 / 84$ & - & - \\
\hline Martens [31] & - & - & $(20) / 89 / 51 / 68$ & - & - & - \\
\hline $\begin{array}{l}\text { Fogel and } \\
\text { colleagues }\end{array}$ & (З3)/100/25/56 & (33)/100/60/77 & - & (33)/100/63/78 & - & (33)/100/65/80 \\
\hline Martens [34] & - & - & $(18) / 67 / 74 / 71$ & - & - & - \\
\hline $\begin{array}{l}\text { Bassetti and } \\
\text { colleagues }\end{array}$ & - & NM & NM & - & - & - \\
\hline $\begin{array}{l}\text { Stelzl and } \\
\text { colleagues }\end{array}$ & $(18) / 100 / 40 / 67$ & (17)/100/83/92 & $\begin{array}{c}(21) / 100 / 100 / \\
100\end{array}$ & $\begin{array}{c}(29) / 100 / 100 / \\
100\end{array}$ & $\begin{array}{c}(36) / 100 / 100 / \\
100\end{array}$ & $\begin{array}{c}(24) / 100 / 100 / \\
100\end{array}$ \\
\hline $\begin{array}{l}\text { Karkela and } \\
\text { colleagues }\end{array}$ & NM & - & NM & - & - & - \\
\hline $\begin{array}{l}\text { Dauberschmidt and } \\
\text { colleagues }\end{array}$ & $(11) / 100 / 43 / 56$ & $(5) / 100 / 50 / 60$ & - & $(5) / 100 / 67 / 78$ & - & $(5) / 100 / 71 / 80$ \\
\hline $\begin{array}{l}\text { Roine and } \\
\text { colleagues }\end{array}$ & - & - & $(17) / 98 / 40 / 80$ & - & - & - \\
\hline \multicolumn{7}{|l|}{ S-100B } \\
\hline $\begin{array}{l}\text { Zandbergen and } \\
\text { colleagues }\end{array}$ & - & - & NM & - & NM & - \\
\hline $\begin{array}{l}\text { Prohl and } \\
\text { colleagues }\end{array}$ & - & $(2.1) / 100 / 17 / 72$ & - & $(1.8) / 100 / 17 / 72$ & - & $(1.2) / 100 / 33 / 78$ \\
\hline $\begin{array}{l}\text { Pfeifer and } \\
\text { colleagues }\end{array}$ & - & NM & - & NM & - & (1.5)/96/34/51 \\
\hline $\begin{array}{l}\text { Zingler and } \\
\text { colleagues }\end{array}$ & $(5.2) / 100 / 35 / 59$ & $(0.8) / 100 / 64 / 77$ & - & $(0.5) / 100 / 75 / 84$ & - & - \\
\hline $\begin{array}{l}\text { Hachimi-Idrissi and } \\
\text { colleagues }\end{array}$ & $(0.7) / 85 / 67 / 78$ & - & $(0.7) / 88 / 100 / 93$ & - & - & - \\
\hline Martens [31] & - & - & $(0.7) / 96 / 55 / 73$ & - & - & - \\
\hline
\end{tabular}

Values in bold are the results of our calculation. cut $=$ values of cutoff points $(\mathrm{ng} / \mathrm{mL}) ;$ spe $=$ specificity $(\%)$; sen $=$ sensitivity $(\%)$; acc $=$ accuracy $(\%)$.

$\mathrm{NM}=$ not mentioned for cutoff values and predictive accuracy; NSE $=$ neuron specific enolase. 


\section{'Return to independent daily life' vs. 'no return to independent daily life'}

Five studies $[17,18,26,29,30]$ investigated the clinical usefulness of NSE and/or S-100B as a prognostic predictor in two outcome groups, 'return to independent daily life' and 'no return to independent daily life'. Table 5 summarizes the results of statistical comparison of serum levels of each biochemical marker between the two groups. Table 6 indicates cut-off values for individual biochemical markers predicting noreturn to independent daily life with the corresponding values of sensitivity, specificity, and accuracy. Tiainen and colleagues [26] divided their study subjects into two treatment groups, 'hypothermia' and 'normothermia' (not undergoing hypother$\mathrm{mia}$ ), and then investigated the prognostic values of both biochemical markers in each group.

Of the five studies mentioned above, two reported serum NSE levels on admission, while two reported serum S-100B levels on admission. No study detected a significant difference in NSE on admission between the two outcome groups, while one study $(1 / 2,50 \%)$ identified a significant difference between them in S-100B on admission. On the other hand, two studies $(2 / 2,100 \%)$ reported a non-significant difference between groups in NSE on admission, while no study reported such a difference in $\mathrm{S}-100 \mathrm{~B}$ on admission (Table 5). These findings suggest that $\mathrm{S}-100 \mathrm{~B}$ assayed on admission may be more useful than NSE assayed concomitantly as an early biochemical predictor of return or no-return to independent daily life.

At no sampling time point other than 'on admission' was any particular tendency noted with respect to the clinical useful- ness of NSE and S-100B as neurological prognostic predictors.

\section{Study design}

Five of the studies reviewed in this article involved uniform application of a blood sampling schedule to all subjects with sampling intervals specified based on a set starting point (e.g., onset of CA, CPR initiation, or ROSC): Auer and colleagues [24] ( $n=17)$, Tiainen and colleagues [26] $(n=36,34)$, Bottiger and colleagues [18] $(n=66)$, Bassetti and colleagues [33] $(n=60)$ and Karkela and colleagues [36] $(n=20)$. However, the sample sizes of these studies were not large. In contrast, four studies including larger numbers of subjects (Grubb and colleagues [14] ( $n=143)$, Reisinger and colleagues [21] ( $n=227)$, Zandbergen and colleagues [22] ( $n=407)$, and Meynaar and colleagues [27] $(n=110))$ involved blood sampling as a part of normal intensive care routine with no attention focused on the intervals of sampling points from onset of CA. Many previous studies demonstrated time-dependent changes in blood levels of these biochemical markers after CA $[18,21,24,25,28,30,32]$. In particular, Bottiger et al. [18] investigated the changes in serum S-100B level within 24 hours after CA in detail, and demonstrated that the serum S100B level varied every hour.

Assessment of the clinical usefulness of S-100B and NSE in predicting post-resuscitative neurological outcome thus requires a study design with particular attention focused on the intervals of sampling points from the onset of $C A$, although no multicenter prospective study using such a study design has been published to date.

Table 5

Comparison of values for biomarkers between no-return and return to independent daily life

\begin{tabular}{|c|c|c|c|c|c|c|c|c|c|}
\hline Authors & Year & Ref & $\mathrm{n}$ & on admission & Day 1 & 24 hours & Day 2 & 48 hours & Day 3 \\
\hline \multicolumn{10}{|l|}{ NSE } \\
\hline Tiainen and colleagues (hypothermia) & 2003 & {$[26]$} & 36 & - & - & NM & NM & NM & - \\
\hline Tiainen and colleagues (normothermia) & 2003 & [26] & 34 & - & - & NM & NM & NM & - \\
\hline Rosen and colleagues & 2001 & [29] & 66 & - & $P<0.05$ & - & $P<0.01$ & - & $P<0.01$ \\
\hline Bottiger and colleagues & 2001 & {$[18]$} & 66 & NS & - & $P<0.05$ & - & $P<0.05$ & - \\
\hline Schoerkhuber and colleagues & 1999 & [30] & 56 & NS & $P<0.01$ & $P<0.05$ & - & $P<0.01$ & - \\
\hline \multicolumn{10}{|l|}{ S-100B } \\
\hline Tiainen and colleagues (hypothermia) & 2003 & {$[26]$} & 36 & - & - & NM & NM & NM & - \\
\hline Tiainen and colleagues (normothermia) & 2003 & {$[26]$} & 34 & - & - & NM & NM & NM & - \\
\hline Mussack and colleagues & 2002 & [17] & 20 & NM & NM & - & - & - & - \\
\hline Rosen and colleagues & 2001 & [29] & 66 & - & $P<0.01$ & - & $P<0.01$ & - & $P<0.01$ \\
\hline Bottiger and colleagues & 2001 & [18] & 66 & $P<0.05$ & - & $P<0.05$ & - & $P<0.05$ & - \\
\hline
\end{tabular}

$\mathrm{NM}=$ not mentioned for statistical comparison; $\mathrm{NS}=$ not significance; NSE $=$ neuron specific enolase, Ref $=$ references. 
Table 6

\begin{tabular}{|c|c|c|c|c|c|c|}
\hline Authors & $\begin{array}{c}\text { on admission } \\
\text { cut/spe/sen/acc }\end{array}$ & $\begin{array}{c}\text { Day } 1 \\
\text { cut/spe/sen/acc }\end{array}$ & $\begin{array}{c}24 \text { hours } \\
\text { cut/spe/sen/acc }\end{array}$ & $\begin{array}{c}\text { Day } 2 \\
\text { cut/spe/sen/acc }\end{array}$ & $\begin{array}{c}48 \text { hours } \\
\text { cut/spe/sen/acc }\end{array}$ & $\begin{array}{c}\text { Day } 3 \\
\text { cut/spe/sen/acc }\end{array}$ \\
\hline \multicolumn{7}{|l|}{ NSE } \\
\hline $\begin{array}{l}\text { Tiainen and colleagues } \\
\text { (hypothermia) }\end{array}$ & - & - & (31)/96/22/76 & $(26) / 96 / 30 / 79$ & (25)/96/25/77 & - \\
\hline $\begin{array}{l}\text { Tiainen and colleagues } \\
\text { (normothermia) }\end{array}$ & - & - & (13)/100/59/80 & $(13) / 100 / 63 / 82$ & (9)/100/76/88 & - \\
\hline Rosen and colleagues & - & $(25) / 100 / 14 / 44$ & - & $(23) / 100 / 34 / 59$ & - & $(13) / 100 / 44 / 69$ \\
\hline Bottiger and colleagues & NM & - & NM & - & NM & - \\
\hline $\begin{array}{l}\text { Schoerkhuber and } \\
\text { colleagues }\end{array}$ & NM & (39)/100/17/59 & $(40) / 100 / 8 / 55$ & - & $(25) / 100 / 48 / 75$ & - \\
\hline $\begin{array}{l}\text { Schoerkhuber and } \\
\text { colleagues }\end{array}$ & NM & $(15) / 72 / 70 / 71$ & $(18) / 80 / 56 / 68$ & - & $(16) / 79 / 72 / 76$ & - \\
\hline \multicolumn{7}{|l|}{ S-100B } \\
\hline $\begin{array}{l}\text { Tiainen } \mathrm{M} \text { and } \\
\text { colleagues } \\
\text { (hypothermia) }\end{array}$ & - & - & $(0.21) / 100 / 30 / 81$ & $(0.2) / 96 / 20 / 76$ & $(0.23) / 96 / 22 / 76$ & - \\
\hline $\begin{array}{l}\text { Tiainen } \mathrm{M} \text { and } \\
\text { colleagues } \\
\text { (normothermia) }\end{array}$ & - & - & $(0.19) / 100 / 59 / 80$ & $(0.5) / 100 / 18 / 59$ & $(0.12) / 100 / 88 / 94$ & - \\
\hline Mussack and colleagues & NM & $(0.76) / 100 / 54 / 62$ & - & - & - & - \\
\hline Rosen and colleagues & - & $(0.4) / 85 / 62 / 70$ & - & $(0.2) / 100 / 67 / 80$ & - & $(0.19) / 100 / 40 / 66$ \\
\hline Bottiger and colleagues & NM & - & NM & - & NM & - \\
\hline
\end{tabular}

Values in bold are the results of our calculation. cut = values of cutoff points $(\mathrm{ng} / \mathrm{mL}) ; \mathrm{spe}=$ specificity $(\%)$; sen $=$ sensitivity $(\%)$; acc $=$ accuracy (\%).

$\mathrm{NM}=$ not mentioned for cutoff values and predictive accuracy; NSE $=$ neuron specific enolase.

\section{Discussion}

Biochemical markers in blood samples can be expected to serve as prognostic predictors of CA patient outcome after CPR and be more easily applicable to clinical practice than neuroimaging or electrophysiological findings. In the present study, we performed a systematic literature review to examine the clinical usefulness of NSE and S-100B (proteins specific to the central nervous system and potential biochemical markers of brain damage) as post-resuscitative predictors of neurological prognosis.

Grubb and colleagues [14] performed the multiple logistic regression analysis on mortality in these biomarkers and clinical scores (i.e., arrest rhythm, bystander CPR and GCS score). They showed that NSE was an independently significant predictor among them. Pfeifer and colleagues [25] compared the neurological predictive value between these biomarkers and the clinical predictors, such as time of anoxia, GCS score, presence of bystander CPR, and so on. Prohl and colleagues [39] also compared this value using clinical examination score reflected some brain stem reflexes. Both studies showed the odds ratio of these clinical predictors was lower than those of NSE and S-100B. Those results indicate that predictive value of biomarkers was superior to that of clinical predictors. Clinical predictors were often affected by the clinical situations (e.g., using of sedative agents, relying on information of emergency medical service personnel who collected information at a chaotic emergency scene). Therefore, the specificity of biomarkers is higher than that of clinical predictors, even though the clinical predictors can be more easily assessed.

NSE is the neuronal form of the cytoplasmic glycolytic enzyme enolase. It is a dimeric enzyme composed of two $\gamma$ subunits $(\gamma \gamma$ isomer) with a total molecular weight of $78 \mathrm{kDa}$ and a biological half-life of 24 hours. It is mainly located in neurons and neuroendocrine cells $[41,42]$. The $\mathrm{S}-100$ protein is a calciumbinding protein with a total molecular weight of $21 \mathrm{kDa}$ and a biological half-life of two hours. S-100B, a homodimer composed of two $\beta$ subunits ( $\beta \beta$ form), is secreted from glial cells and Schwann cells [43]. Recent studies have suggested that elevated levels of S-100B might cause neuronal apoptosis, suggesting that $\mathrm{S}-100 \mathrm{~B}$ may play a role as a cytokine in brain inflammatory responses $[44,45]$. Accordingly, in patients with high serum levels of S-100B after CPR, S-100B when present at high levels in the brain is suspected to induce brain cell 
apoptosis leading to aggravation of post-CA brain injury. S$100 \mathrm{~B}$ is also considered a putative 'Alarmin' released during an early stage of the inflammatory response [46].

The findings of the present study suggest that, when assayed 'on admission' (i.e., within eight hours after CA), serum levels of S-100B might be more clinically useful than those of NSE in predicting neurological outcomes such as regaining consciousness and returning to independent daily life. Assay of serum S-100B level focuses on the process of aggravation of brain injury, while brain imaging, physical examination, and electrophysiology all focus on the consequences of brain injury. NSE is a protein located in nerve cells and detectable in body fluids as a marker enzyme indicative of nerve cell injury [47]. Monitoring for increases in the serum NSE level thus focuses on cell death as a result of post-CA brain injury. Consequently, S-100B serves as a prognostic predictor within 24 hours after $\mathrm{CA}$, and thus at an earlier stage than other factors (including NSE), which focus on the consequences of brain injury and are therefore meaningful as prognostic predictors one to three days after CA (i.e., only after manifestation of brain injury is completed) $[1,22]$.

Many preceding studies recognized an increase in serum NES level over time in patients with poor outcome after CPR, and also demonstrated a decrease in serum S-100B level over time in those with favorable outcome [14,21,25,26,28-30]. In those studies, these changes were ascribed to the difference in biological half-life between these two proteins. However, it should be noted that these changes can also be explained by considering $\mathrm{S}-100 \mathrm{~B}$ a cause of post-CA brain injury and NSE, an enzyme released from nerve cells, as a result of brain injury: NSE as a marker of brain cell injury increases over time and accumulates as a result of aggravation of brain injury, while persistence of $\mathrm{S}-100 \mathrm{~B}$ as a cause of brain injury at high levels leads to aggravation of disease, a conclusion consistent with the previously reported findings.

Therefore, we emphasize that the time-course change in early phase of serum S-100B and NSE levels would offer a more reliable indication of what is happening in the brain of the CA patient, which might be useful for optimization of therapeutic intervention in future cases of CA. However, there are few investigations on the time-course of these biomarkers. Usui and colleagues [48] reported the detailed time-course of these biomarkers in serum and cerebrospinal fluid every one to two hours within 18 hours after CA in mongrel dog models. Bottiger and colleagues [18] reported the time-course of human serum $\mathrm{S}-100 \mathrm{~B}$ every 15 minutes within 1 hour and at 2, 8, and 24 hours after CA. However, this study by Bottiger and colleagues is limited by the number of subjects. Therefore, there is no investigation on the time-course of these biomarkers involving a large number of human subjects. The future investigators should put more weight on the time-course change of the biomarkers, especially the changes in early phase (i.e., within 24 hours following CA).

The present study identified 24 original articles involving investigation of the clinical usefulness of NSE and S-100B as prognostic predictors of CA patients after CPR. The design adopted varied from study to study, making a systematic literature review extremely difficult $[10,40]$. The major problems encountered during the review process involved variation or heterogeneity among studies in the following three respects: definitions of outcome to be assessed (e.g., some studies adopted grouping criteria for outcome different from others); the value of specificity corresponding to each cut-off value reported for a particular biochemical marker predictive of a poor prognosis (i.e., not always fixed at 100\%); and specification of blood sampling time points (i.e., not always uniform application of a blood sampling schedule to all subjects with sampling intervals specified).

Consistency in the three respects noted above had not been considered in the five review articles previously published on the same subject $[1,2,9,10,40]$, and the present review is the first attempt to consider it.

A recently published article discusses pitfalls in critical care meta-analysis [49], highlighting publication bias and trial-level heterogeneity as pitfalls to be carefully avoided in a systematic review of observational studies such as the present review. To avoid publication bias, we performed an extensive literature search to identify all papers published previously on the clinical usefulness of NSE and S-100B in prediction of prognosis after resuscitation from CA and closely reviewed the full-text contents of all papers thus identified. Trial-level heterogeneities encountered in papers reviewed in the present study include grouping criteria for outcome (definitions of outcome), specification of time points for blood sampling, and assay procedures for individual biochemical markers of interest. Consistency in definitions of outcome and specification of time points for blood sampling appears to be particularly important in the present literature review investigating the clinical usefulness of serum levels of NSE and S-100B as prognostic predictors.

Rapid interdisciplinary treatment and monitoring are required in the early post-resuscitative period, sometimes including percutaneous coronary intervention as well. Consequently, a study design involving uniform blood sampling within a few hours after resuscitation would be difficult to adopt in a multicenter study. Rosen and colleagues [29] studied 66 out-ofhospital CA and collected blood samples at various time points according to their ward routines. Their mean first sample times ( \pm standard error) were $10.5 \pm 0.9$ hours after CA. In consideration of these results, we think that blood sampling at least once between 4 and 12 hours after resuscitation would be practicable and adoptable. Therefore, a multicenter 
prospective study involving blood sampling between 4 and 12 hours after resuscitation at a time point specified by interval from onset of CA would be most helpful in investigating the clinical usefulness of S-100B and NSE as early predictors of neurological outcome of CA patients after CPR.

The present review, which included all previous papers identified in a literature search, included a paper published in 1989 [38] as the earliest published report. In the past 20 years, however, techniques of assay for both NSE and S-100B have been greatly improved, with concomitant increase in sensitivity of detection [50,51]. It is therefore difficult, and even inappropriate, to assess the cut-off values reported for serum levels of these biochemical markers during this period using a uniform scale or standard.

Finally, we emphasize that extracellular S100B at $\mu \mathrm{M}$ concentration is harmful to astrocyte and neurons but at $\mathrm{nM}$ concentrations is beneficial to those $[45,52]$. Thus, at least at the very beginning of brain injury the secretion and release of $\mathrm{S} 100 \mathrm{~B}$ (and hence elevation of serum S100B levels, if any) might not necessarily be indicative of aggravation of brain injury; it may be indicative of activation of astrocytes and attempt to provide neurons with a trophic factor. Thus, it may be important that the levels of serum S100B and NSE be measured at the very onset of $\mathrm{CA}$ and at intervals during the next few hours. An analysis of the time-course of serum S100B and NSE levels would offer a more reliable indication of what is going on in the brain of the patient, which might be useful for optimization of therapeutic intervention in future cases.

\section{Conclusions}

The present study shows that the measurements of serum levels of S100B within 24 hours after CA might be clinically more relevant than those of NSE in predicting neurological outcomes.

As noted above, no systematic literature review has been performed including all previously published papers on the clinical usefulness of NSE and S-100B as neurological prognostic predictors. In such circumstances, the findings of the present study should aid future investigators in examining the clinical usefulness of these biochemical markers and determination of cut-off values predictive of poor neurological outcome.

\section{Competing interests}

The authors declare that they have no competing interests.

\section{Authors' contributions}

$\mathrm{KS}$ conceived and designed the study. $\mathrm{OS}$ and $\mathrm{HH}$ made critical revision of the manuscript for important intellectual content. TS, MN, YH, RA, YT, NH, and TS drafted the manuscript. All authors read and approved the final manuscript.

\section{Key messages}

- A consistent definition of poor (good) outcome should be used in assessing data from multiple studies.

- The cut-off values for neurological predictors after CPR should be set so that specificity in prediction of poor outcome is $100 \%$.

- The time points of blood sampling should be fixed in assessing the time course of change in blood levels of NSE and S-100B.

- S-100B assayed on admission may be more useful than NSE assayed concomitantly as an early biochemical predictor of remaining comatose and no-return to independent daily life.

- A multicenter prospective study involving blood sampling after resuscitation at a time point specified by interval from onset of CA would be most helpful in investigating the clinical usefulness of S-100B and NSE as early predictors of neurological outcome.

\section{Authors' information}

KS: Clinical Fellow, Department of Emergency and Critical Care Medicine, Chiba University Hospital, Board Certified Member of Japanese Society of Intensive Care Medicine.

OS: Professor and Chairman, Department of Emergency and Critical Care Medicine, Chiba University Graduate School of Medicine, Board Certified Member of Japanese Society of Intensive Care Medicine.

$\mathrm{HH}$ : Professor Emeritus and Former Chairman, Department of Emergency and Critical Care Medicine, Chiba University Graduate School of Medicine, Immediate Past President of Japanese Society of Intensive Care Medicine

\section{Acknowledgements}

KS was supported by Grant-in-Aid for Young Scientists (Category B 20791321) from the Ministry of Education, Culture, Sports, Science and Technology Japan.

\section{References}

1. Wijdicks EF, Hijdra A, Young GB, Bassetti CL, Wiebe S: Practice parameter: prediction of outcome in comatose survivors after cardiopulmonary resuscitation (an evidence-based review): report of the Quality Standards Subcommittee of the American Academy of Neurology. Neurology 2006, 67:203-210.

2. Puttgen HA, Geocadin R: Predicting neurological outcome following cardiac arrest. J Neurol Sci 2007, 261:108-117.

3. Cummins RO, Chamberlain D, Hazinski MF, Nadkarni V, Kloeck W, Kramer E, Becker L, Robertson C, Koster R, Zaritsky A, Bossaert L, Ornato JP, Callanan V, Allen M, Steen P, Connolly B, Sanders A, Idris $A$, Cobbe $S$ : Recommended guidelines for reviewing, reporting, and conducting research on in-hospital resuscitation: the in-hospital 'Utstein style'. A statement for healthcare professionals from the American Heart Association, the European Resuscitation Council, the Heart and Stroke Foundation of Canada, the Australian Resuscitation Council, and the Resuscitation Councils of Southern Africa. Resuscitation 1997, 34:151-183. 
4. Cummins RO, Chamberlain DA, Abramson NS, Allen M, Baskett PJ, Becker L, Bossaert L, Delooz HH, Dick WF, Eisenberg MS, Evans TR, Holmberg S, Kerber R, Mullie A, Ornato JP, Sandoe E, Skulberg A, Tunstall-Pedoe H, Swanson R, Thies WH: Recommended guidelines for uniform reporting of data from out-ofhospital cardiac arrest: the Utstein Style. A statement for health professionals from a task force of the American Heart Association, the European Resuscitation Council, the Heart and Stroke Foundation of Canada, and the Australian Resuscitation Council. Circulation 1991, 84:960-975.

5. Jacobs I, Nadkarni V, Bahr J, Berg RA, Billi JE, Bossaert L, Cassan P, Coovadia A, D'Este K, Finn J, Halperin H, Handley A, Herlitz J, Hickey R, Idris A, Kloeck W, Larkin GL, Mancini ME, Mason P, Mears G, Monsieurs K, Montgomery W, Morley P, Nichol G, Nolan J, Okada K, Perlman J, Shuster M, Steen PA, Sterz F, Tibballs J, Timerman S, Truitt T, Zideman D: Cardiac arrest and cardiopulmonary resuscitation outcome reports: update and simplification of the Utstein templates for resuscitation registries: a statement for healthcare professionals from a task force of the International Liaison Committee on Resuscitation (American Heart Association, European Resuscitation Council, Australian Resuscitation Council, New Zealand Resuscitation Council, Heart and Stroke Foundation of Canada, InterAmerican Heart Foundation, Resuscitation Councils of Southern Africa). Circulation 2004, 110:3385-3397.

6. Becker LB, Han BH, Meyer PM, Wright FA, Rhodes KV, Smith DW, Barrett J: Racial differences in the incidence of cardiac arrest and subsequent survival. The CPR Chicago Project. $N$ Engl J Med 1993, 329:600-606.

7. Kellermann AL, Hackman BB, Somes G: Predicting the outcome of unsuccessful prehospital advanced cardiac life support. JAMA 1993, 270:1433-1436.

8. Langhelle A, Nolan J, Herlitz J, Castren M, Wenzel V, Soreide E, Engdahl J, Steen PA: Recommended guidelines for reviewing, reporting, and conducting research on post-resuscitation care: the Utstein style. Resuscitation 2005, 66:271-283.

9. Zandbergen EG, de Haan RJ, Hijdra A: Systematic review of prediction of poor outcome in anoxic-ischaemic coma with biochemical markers of brain damage. Intensive Care Med 2001, 27:1661-1667.

10. Ekmektzoglou KA, Xanthos T, Papadimitriou L: Biochemical markers (NSE, S-100, IL-8) as predictors of neurological outcome in patients after cardiac arrest and return of spontaneous circulation. Resuscitation 2007, 75:219-228.

11. A randomized clinical study of cardiopulmonary-cerebral resuscitation: design, methods, and patient characteristics. Brain Resuscitation Clinical Trial I Study Group. Am J Emerg Med 1986, 4:72-86.

12. Jennett $B$, Bond $M$ : Assessment of outcome after severe brain damage. Lancet 1975, 1:480-484.

13. Jennett B, Snoek J, Bond MR, Brooks N: Disability after severe head injury: observations on the use of the Glasgow Outcome Scale. J Neurol Neurosurg Psychiatry 1981, 44:285-293.

14. Grubb NR, Simpson C, Sherwood RA, Abraha HD, Cobbe SM, O'Carroll RE, Deary I, Fox KA: Prediction of cognitive dysfunction after resuscitation from out-of-hospital cardiac arrest using serum neuron-specific enolase and protein S-100. Heart 2007, 93:1268-1273.

15. Hachimi-Idrissi S, Zizi M, Nguyen DN, Schiettecate J, Ebinger G, Michotte $Y$, Huyghens $L$ : The evolution of serum astroglial S100 beta protein in patients with cardiac arrest treated with mild hypothermia. Resuscitation 2005, 64:187-192.

16. Hachimi-Idrissi S, Auwera M Van der, Schiettecatte J, Ebinger G, Michotte $Y$, Huyghens L: S-100 protein as early predictor of regaining consciousness after out of hospital cardiac arrest. Resuscitation 2002, 53:251-257.

17. Mussack T, Biberthaler P, Kanz KG, Wiedemann E, Gippner-Steppert C, Mutschler W, Jochum M: Serum S-100B and interleukin8 as predictive markers for comparative neurologic outcome analysis of patients after cardiac arrest and severe traumatic brain injury. Crit Care Med 2002, 30:2669-2674.

18. Bottiger BW, Mobes S, Glatzer R, Bauer H, Gries A, Bartsch P, Motsch J, Martin E: Astroglial protein S-100 is an early and sensitive marker of hypoxic brain damage and outcome after cardiac arrest in humans. Circulation 2001, 103:2694-2698.

19. Mussack T, Biberthaler $P$, Kanz KG, Wiedemann E, Gippner-Steppert C, Jochum M: S-100b, sE-selectin, and sP-selectin for eval- uation of hypoxic brain damage in patients after cardiopulmonary resuscitation: pilot study. World J Surg 2001, 25:539-543.

20. Rosen H, Rosengren L, Herlitz J, Blomstrand C: Increased serum levels of the S-100 protein are associated with hypoxic brain damage after cardiac arrest. Stroke 1998, 29:473-477.

21. Reisinger J, Hollinger $K$, Lang $W$, Steiner $C$, Winter T, Zeindlhofer E, Mori M, Schiller A, Lindorfer A, Wiesinger K, Siostrzonek P: Prediction of neurological outcome after cardiopulmonary resuscitation by serial determination of serum neuron-specific enolase. Eur Heart J 2007, 28:52-58.

22. Zandbergen EG, Hijdra A, Koelman JH, Hart AA, Vos PE, Verbeek $\mathrm{MM}$, de Haan RJ: Prediction of poor outcome within the first 3 days of postanoxic coma. Neurology 2006, 66:62-68.

23. Rech TH, Vieira SR, Nagel F, Brauner JS, Scalco R: Serum neuron-specific enolase as early predictor of outcome after inhospital cardiac arrest: a cohort study. Crit Care 2006, 10:R133.

24. Auer J, Berent R, Weber T, Porodko M, Lamm G, Lassnig E, Maurer $E$, Mayr $H$, Punzengruber $C$, Eber B: Ability of neuron-specific enolase to predict survival to hospital discharge after successful cardiopulmonary resuscitation. CJEM 2006, 8:13-18.

25. Pfeifer R, Borner A, Krack A, Sigusch HH, Surber R, Figulla HR: Outcome after cardiac arrest: predictive values and limitations of the neuroproteins neuron-specific enolase and protein $S$ 100 and the Glasgow Coma Scale. Resuscitation 2005 65:49-55.

26. Tiainen M, Roine RO, Pettila V, Takkunen O: Serum neuron-specific enolase and $\mathrm{S}-100 \mathrm{~B}$ protein in cardiac arrest patients treated with hypothermia. Stroke 2003, 34:2881-2886.

27. Meynaar IA, Straaten HM, Wetering J van der, Verlooy $P$, Slaats $\mathrm{EH}$, Bosman RJ, Spoel Jl van der, Zandstra DF: Serum neuronspecific enolase predicts outcome in post-anoxic coma: a prospective cohort study. Intensive Care Med 2003, 29:189-195.

28. Zingler VC, Krumm B, Bertsch T, Fassbender K, Pohlmann Eden $\mathrm{B}$ : Early prediction of neurological outcome after cardiopulmonary resuscitation: a multimodal approach combining neurobiochemical and electrophysiological investigations may provide high prognostic certainty in patients after cardiac arrest. Eur Neurol 2003, 49:79-84.

29. Rosen H, Sunnerhagen KS, Herlitz J, Blomstrand C, Rosengren L: Serum levels of the brain-derived proteins S-100 and NSE predict long-term outcome after cardiac arrest. Resuscitation 2001, 49:183-191.

30. Schoerkhuber W, Kittler H, Sterz F, Behringer W, Holzer M, Frossard M, Spitzauer S, Laggner AN: Time course of serum neuronspecific enolase. A predictor of neurological outcome in patients resuscitated from cardiac arrest. Stroke 1999, 30:1598-1603

31. Martens P, Raabe A, Johnsson P: Serum S-100 and neuron-specific enolase for prediction of regaining consciousness after global cerebral ischemia. Stroke 1998, 29:2363-2366.

32. Fogel W, Krieger D, Veith M, Adams HP, Hund E, Storch Hagenlocher B, Buggle F, Mathias D, Hacke W: Serum neuron-specific enolase as early predictor of outcome after cardiac arrest. Crit Care Med 1997, 25:1133-1138.

33. Bassetti C, Bomio F, Mathis J, Hess CW: Early prognosis in coma after cardiac arrest: a prospective clinical, electrophysiological, and biochemical study of 60 patients. I Neurol Neurosurg Psychiatry 1996, 61:610-615.

34. Martens P: Serum neuron-specific enolase as a prognostic marker for irreversible brain damage in comatose cardiac arrest survivors. Acad Emerg Med 1996, 3:126-131.

35. Stelzl T, von Bose MJ, Hogl B, Fuchs HH, Flugel KA: A comparison of the prognostic value of neuron-specific enolase serum levels and somatosensory evoked potentials in 13 reanimated patients. Eur J Emerg Med 1995, 2:24-27.

36. Karkela J, Bock E, Kaukinen S: CSF and serum brain-specific creatine kinase isoenzyme (CK-BB), neuron-specific enolase (NSE) and neural cell adhesion molecule (NCAM) as prognostic markers for hypoxic brain injury after cardiac arrest in man. J Neurol Sci 1993, 116:100-109.

37. Dauberschmidt R, Zinsmeyer J, Mrochen H, Meyer M: Changes of neuron-specific enolase concentration in plasma after cardiac arrest and resuscitation. Mol Chem Neuropathol 1991, 14:237-245. 
38. Roine RO, Somer H, Kaste M, Viinikka L, Karonen SL: Neurological outcome after out-of-hospital cardiac arrest. Prediction by cerebrospinal fluid enzyme analysis. Arch Neurol 1989, 46:753-756.

39. Prohl J, Rother J, Kluge S, de Heer G, Liepert J, Bodenburg S, Pawlik K, Kreymann G: Prediction of short-term and long-term outcomes after cardiac arrest: a prospective multivariate approach combining biochemical, clinical, electrophysiological, and neuropsychological investigations. Crit Care Med 2007, 35:1230-1237.

40. Snyder-Ramos SA, Bottiger BW: Molecular markers of brain damage - clinical and ethical implications with particular focus on cardiac arrest. Restor Neurol Neurosci 2003, 21:123-139.

41. Schmechel D, Marangos PJ, Brightman M: Neurone-specific enolase is a molecular marker for peripheral and central neuroendocrine cells. Nature 1978, 276:834-836.

42. Pahlman S, Esscher T, Bergvall P, Odelstad L: Purification and characterization of human neuron-specific enolase: radioimmunoassay development. Tumour Biol 1984, 5:127-139.

43. Schafer BW, Heizmann CW: The S100 family of EF-hand calcium-binding proteins: functions and pathology. Trends Biochem Sci 1996, 21:134-140.

44. Bianchi R, Adami C, Giambanco I, Donato R: S100B binding to RAGE in microglia stimulates COX-2 expression. $J$ Leukoc Biol 2007, 81:108-118.

45. Van Eldik $\sqcup$, Wainwright MS: The Janus face of glial-derived S100B: beneficial and detrimental functions in the brain. Restor Neurol Neurosci 2003, 21:97-108.

46. Bianchi ME: DAMPs, PAMPs and alarmins: all we need to know about danger. J Leukoc Biol 2007, 81:1-5.

47. Marangos PJ, Schmechel DE: Neuron specific enolase, a clinically useful marker for neurons and neuroendocrine cells. Annu Rev Neurosci 1987, 10:269-295.

48. Usui A, Kato K, Murase M, Hotta T, Tanaka M, Takeuchi E, Abe T: Neural tissue-related proteins (NSE, G0 alpha, 28-kDa calbindin-D, S100b and CK-BB) in serum and cerebrospinal fluid after cardiac arrest. J Neuro/ Sci 1994, 123:134-139.

49. Reade MC, Delaney A, Bailey MJ, Angus DC: Bench-to-bedside review: Avoiding pitfalls in critical care meta-analysis - funnel plots, risk estimates, types of heterogeneity, baseline risk and the ecologic fallacy. Crit Care 2008, 12:220.

50. Smit LH, Korse CM, Bonfrer JM: Comparison of four different assays for determination of serum S-100B. Int J Biol Markers 2005, 20:34-42.

51. Heizmann CW: S100B protein in clinical diagnostics: assay specificity. Clin Chem 2004, 50:249-251.

52. Donato R, Sorci G, Riuzzi F, Arcuri C, Bianchi R, Brozzi F, Tubaro C, Giambanco I: S100B's double life: Intracellular regulator and extracellular signal. Biochim Biophys Acta 2009, 1793:1008-1022. 